\title{
APPLYING A BENCHMARKING METHODOLOGY TO EMPOWER A VIRTUAL ORGANISATION
}

\author{
Rolando Vargas Vallejos ${ }^{1}$; Jefferson de Oliveira Gomes ${ }^{2}$ \\ ${ }^{1}$ Universidade de Caxias do Sul, BRAZIL (rvvallej@ucs.br) \\ 2. Instituto Tecnológico de Aeronáutica,BRAZIL (gomes@ita.br)
}

\begin{abstract}
This paper describes an experience applying a benchmarking methodology in a Virtual Organisation (VO) called Virfebras. A peculiar characteristic of Virfebras is that enterprises 'members are competitors, but entrepreneurs are convinced that they have to work co-operatively in order to achieve common business-related goals.

The creation of Virfebras went through several phases. One of these phases, benchmarking, is considered important to supply strategic technological information and to empower entrepreneurs' behaviour, increasing trust between them. The present work describes the benchmarking methodology developed for seven mould and die enterprises, which a re part of a Virtual Organisation called Virfebras.
\end{abstract}

\section{INTRODUCTION}

Mould and die manufacturing occupies a key position in the industrial value-added chain. The effectiveness of this sector exerts considerable influence on the competitiveness of production companies (Eversheim \& Klocke, 1998).

According to Eversheim and Weber (2000), mould and die external boundary conditions are high pressure of time and cost as well as high quality standards caused by fierce competition, new technological developments and lack of qualified personnel. Internal boundary conditions are a complex production system of "oneof-a-kind" tools for a high product spectrum that are disturbed by a high percentage of alteration orders, repair orders and rush orders. Because of these conditions work environment of mould and die industries is always in turbulence.

To minimise this work environment turbulence, some concepts, philosophies, techniques, methods and tools are being used. One of these methods is benchmarking, which is used for measuring cost structures, processes and technological performance of enterprises, and to provide them with strategic information, which will lead to highest competitiveness (Kiesel, 2001).

In the present work a benchmarking methodology for the Virfebras Virtual Organization (VO) was developed and applied. The methodology was adapted from the successful German experience of the "Aachener Werkzeug- und Formenbau" in the mould and die sector. This experience is a mutual business effort of the Fraunhofer Institute for Production Technology (IPT) and the Laboratory for 
Machine Tools and Production Engineering (WZL) at RWTH Aachen. Virfebras is composed of nine mould and die industries, and its characteristics are described below.

\section{THE VIRFEBRAS VO}

Virfebras is a VO that resulted from the partnership between the University of Caxias do Sul (UCS), nine mould and die industries, a Brazilian agency for supporting small and medium size companies (SEBRAE-RS), and the State of Rio Grande do Sul government. These companies, which have common market interests, decided to take part in a research project co-ordinated by UCS with the purpose of learning how to build a cooperative environment using ICT (Galelli et al., 2001).

Initially, Virfebras adopted the concepts of Virtual Enterprise (VE) and VO proposed by Camarinha-Matos and Afsarmanesh: " $A V E$ is a temporary alliance of enterprises that come together to share skills or core competencies and resources in order to better respond to business opportunities, and whose co-operation is supported by computer networks. $A$ VO is a concept similar to a virtual enterprise, comprising a network of organisations that share resources and skills to achieve its mission'goal, but not limited to an alliance of enterprises" (Camarinha-Matos \& Afsarmanesh, 1999). As the concepts of VO and VE were new, one of the major challenges was to set up a VO without previous knowledge of this area. This way, entrepreneurs and professors, until now, have been discussing concepts and operational issues of VO and VE and applying them to their own companies.

Virfebras was created in 1999 and is located in the city of Caxias do Sul, south of Brazil. Whenever an order is submitted to the group, a VE is created, with one of the companies being the co-ordinator (VE-C), and other companies being the members (VE-M). The VE-C takes responsibility on the technical and legal aspects of the order. When the mould(s) and/or die(s) are delivered to the customer, and there are no more issues to deal with that order, the VE is dissolved. This way, within the VO, several VEs may exist at the same time, with one specific company being co-ordinator of one or more VEs, and member of others. It is worth mentioning that every company keeps its identity, and is also allowed to do business alone.

The creation of Virfebras went through several phases, namely training and education, technology set up, market strategy, benchmarking, identification of shareable resources, organisational structure, and operational issues (Galelli et al., 2001). In the present work, one of these phases, benchmarking, is considered important to provide strategic technological information, and to empower the entrepreneurs' behaviour increasing trust between them. The authors state that benchmarking should be considered as a strategic activity to increase the integration and performance of enterprises that are involved in a VO.

\section{BENCHMARKING}

Learning from the practices of others is part of human nature. We apply this principle intuitively at home, at work, in the society, wherever we are. 
Benchmarking follows this same basic principle, trying to systematise and apply it in organisations with the purpose to supply them with strategic information.

There a re several types a nd models of b enchmarking. In the present work we will explore the competitive benchmarking, characterised by its application between competitors. The idea is that competitors have, if not the same practices, very similar ones; they have the same problems and common solutions too.

Benchmarking is a continuous and systematic process to evaluate products, services and processes against competitors, or renowned organisations considered world leaders in their field (Spendolini, 1993; Zairi \& Leonard, 1996). The working definition is the search for industry best practices that lead to superior performance. According to Zairi and Leonard (1996), benchmarking is used at the strategic level to determine performance standards considering four corporate priorities: customer satisfaction, employee motivation and satisfaction, market share and return on assets, and at the operational level to understand the best practices or processes that help others achieve world-class performance.

Benchmarking is an opportunity for an organisation to learn from the experience of others. Even considering benchmarking an experience that stimulates selfquestioning organisation processes will bring benefits, because a constructive crisis and challenging ideas and practices is beneficial per se (Boxwell, 1996; Zairi \& Leonard, 1996).

\section{BENCHMARKING FOR MOULD AND DIE INDUSTRIES}

Mould and die manufacturing occupies a key position in the industrial value-added chain. A recent benchmarking work in Europe involving approximately 50 mould and die makers in Europe and South America (Eversheim et al., 2001) identifies some common characteristics of high performing enterprises. In addition, five factors were identified that have a high degree of correlation with those high performing enterprises. These factors are listed below:

a. Focus on the processes. Enterprises had clearly defined core competencies on processes and had developed specifics market niches.

b. A higher effort was extended to project and design in the production life cycle. Project planning and engineering attention was intensified before shop floor activities.

c. Continuous investments and improvement on their chosen core competencies.

d. Increased machine tool utilization reducing set up times. CNC programming was rigorously developed using integrated resources and methods.

e. Highly motivated workforce. Employees enjoy their work, and care about company performance.

The study found that companies that excelled at these practices had experienced superior performance and efficiency, more than $25 \%$ lower lead-time to produce moulds and dies.

Based on that experience and a dapting it to s ome $B$ razilian market $r$ ealities, a benchmarking methodology was developed for the enterprises that a re $p$ art of the Virfebras VO. The question was: if benchmarking helps mould and die enterprises to be more competitive, how will affect the entrepreneur's relationship in a VO? 


\section{THE VIRFEBRAS BENCHMARKING PROJECT}

The mould and die enterprises that form the Virfebras VO, in almost four years, have learned how to work in a co-operative environment. Currently, with this strategy, these enterprises offer a broader range of quality services to their customers, including lower costs and lower time-to-market.

The benchmarking project was an initiative of seven enterprises of Virfebras, which wanted to compare and evaluate their technological resources and processes, identifying their practices between the "best and worst practices" of the group through specific technological performance parameters.

The benchmarking methodology is divided in five phases called: planning (identification of technological performance parameters, elaboration of the benchmarking questionnaire and its application), creation and analysis of Virfebras database, integration (interpretation and discussion of the technological performance parameters with the group), action (planning actions to increase lower performance parameters of the group and of each enterprise, and apply them), and checking (the processes performances).

To analyse the technological performance parameters based on the "Aachener Werkzeug- und Formenbau experience" (Klocke \& Bilsing, 2002), the "analysis of pairs" methodology was applied. This method is used to verify the number of prevalent qualitative parameters, in a context where it is not possible to establish a comparison numerically. In that way it is possible to establish a ranking of weights for certain technological characteristics.

To exemplify this methodology for the analysis of the technological characteristics of $\mathrm{CNC}$ milling machines for the mould and die sector, it is possible to link some parameters, as listed below:

1. Spindle power and speed; 2. Machining area; 3 . CNC; 4 . Work piece pallet; 5 . Tool changer; 6. CAM interface; 7. Number of machines per operator; 8 . Integrated measuring system; 9 . etc..

Table 1 - Matrix for the "analysis of pairs" methodology considering a specific context (mould and die sector, roughness process, etc.) for milling machines

\begin{tabular}{|l|c|c|c|c|c|c|c|}
\hline & 1 & 2 & 3 & 4 & 5 & 6 & 7 \\
\hline 1. Spindle power and speed & & & & & & & \\
\hline 2. Machining area & 1 & & & & & & \\
\hline 3. CNC & 1 & 2 & & & & & \\
\hline 4. Work piece pallet & 1 & 2 & 3 & & & & \\
\hline 5. Tool changer & 1 & 2 & 3 & 5 & & & \\
\hline 6. CAM interface & 1 & 2 & 3 & 6 & 6 & & \\
\hline 7. Number of machines per operator & 1 & 2 & 3 & 7 & 7 & 6 & \\
\hline 8. Integrated measuring system & 1 & 2 & 3 & 8 & 5 & 6 & 7 \\
\hline 9. etc. & & & & & & & \\
\hline
\end{tabular}

With the information of Table 1 it is possible to establish a ranking of "weights" for certain technological characteristics (Table 2). To calculate the qualitative parameters' "weight", can be used the following equation:

Weight $=\left[4\left(\mathrm{~N}_{\mathrm{i}}-\mathrm{N}_{\min }\right) /\left(\mathrm{N}_{\max }-\mathrm{N}_{\min }\right)+1\right]$ 
Table 2 - Ranking of "weights" for certain technological characteristics

\begin{tabular}{|l|l|l|l|l|}
\hline Characteristics & $\begin{array}{l}\text { Number of citations in } \\
\text { the "analysis of pairs" }\end{array}$ & $\begin{array}{l}\text { Characteristic's } \\
\text { weights }\end{array}$ & $\begin{array}{l}\text { Characteristic's } \\
\text { usefulness }\end{array}$ & $\begin{array}{c}\text { Weight } x \\
\text { Usefulness }\end{array}$ \\
\hline 1 & 7 & 5 & 2 & 10 \\
\hline 2 & 6 & 4 & 2 & 8 \\
\hline 3 & 5 & 4 & 2 & 8 \\
\hline 4 & 0 & 1 & 0 & 0 \\
\hline 5 & 2 & 2 & 1 & 2 \\
\hline 6 & 4 & 3 & 2 & 6 \\
\hline 7 & 3 & 3 & 2 & 6 \\
\hline 8 & 1 & 2 & 1 & 2 \\
\hline Total & & & & 42 \\
\hline
\end{tabular}

For the usefulness the criteria are: 0 - they don't use the characteristic, 1 - they use it sometimes, and 2 - they use it frequently.

Considering the characteristic's weight and usefulness we obtain a total value that is divided by the maximum factor acquired for that analysis. This result is multiplied by 5 to obtain the technological factor:

$$
\mathrm{K}_{\text {tech }}=5 \times\left[\text { Tota }_{\text {used }} / \text { Total }_{\text {disp }}\right]
$$

\section{RESULTS}

The first result of this benchmarking methodology is summarised in more than 100 benchmarking figures describing several technological performance parameters that measure the organisational and technological performance of the mould and die enterprises that compose Virfebras.

Based on the technological factors of the E uropean b enchmarking project, the following associations were established with the Virfebras VO:

a. Focus on the processes. The Virfebras enterprises have not clearly identified their core competencies, and developed their market niches yet. Some companies had defined their competencies to manufacture injection moulds, others stamping tools, but without a specific process specialization. The moulds and dies are mostly of medium size and weight. The request for surface quality and dimensional tolerances are uncritical.

b. Moulds design / manufacturing lead-time. The companies apply lower time project and process planning comparing to the shop floor activities, which leads to a high effort to finishing and machining process stages (Figure 1).

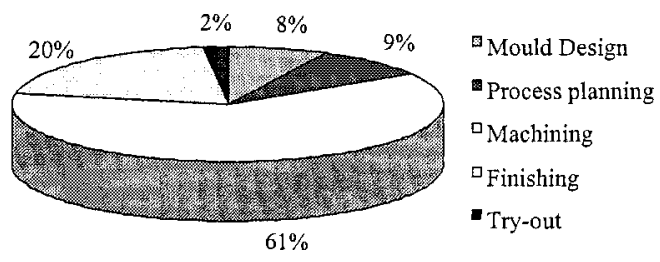

Figure 1 - Percentage of Virfebras moulds design / manufacturing lead-time. 
In addition, the analysis shows that about $60 \%$ of the total costs are dedicated to tool production, which means high percentage personnel cost and low automation grade. Despite high personal cost, the number of specialists is low and, therefore, the projects do not usually have innovative solutions.

c. Machine equipment. During the efficiency evaluation of the machines the five main manufacturing p rocesses in mould and die industry, respectively milling, sink and wire Electrical Discharge Machining (EDM), grinding, turning, were examined. For the evaluation some features were determined, related to a technological factor $\left(\mathrm{K}_{\mathrm{tech}}\right)$, thus enabling an evaluation independent of the type of operation. To exemplify this analysis some figures describing the milling and the EDM processes are showed.

d. Milling machines. The enterprises within the Virfebras VO have a generic spectrum of milling machines, which covers all areas of different milling operations, roughing processes up to the High Speed Cutting (HSC) milling, except HSC for non ferrous (Figure 2).

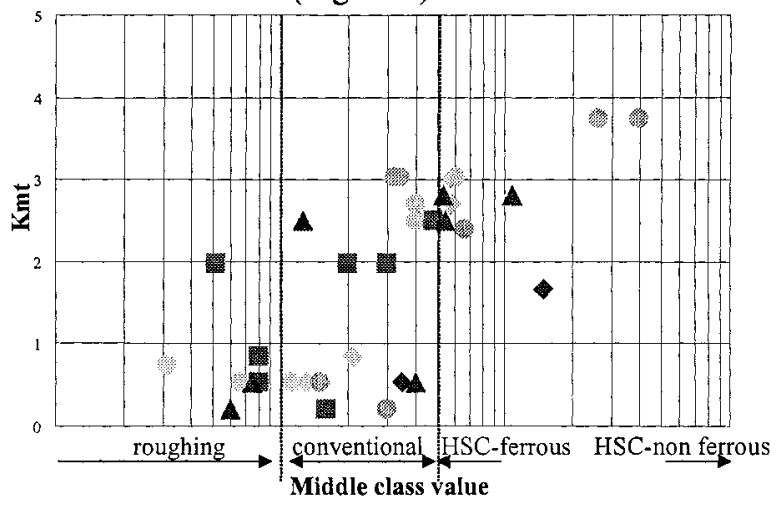

Figure 2 - Technological characteristics of Virfebras milling machines.

e. EDM machines and processes. The sink-EDM e valuation presented a low efficiency. The main reason for this is the low machine running time and low automation process. However, the wire-EDM evaluation presented a better efficiency, due to strong investment in new machines and better machine running time (Figure 3 ).
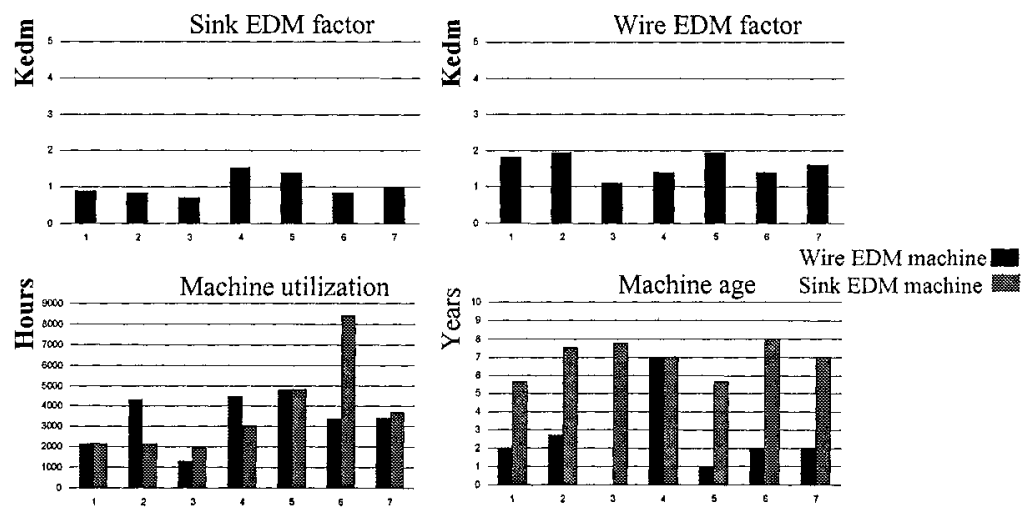

Figure 3 - Analysis of Virfebras EDM machines and EDM processes. 


\subsection{Comments}

After the $c$ reation and a nalysis of the $V$ irfebras $d$ atabase an integration workshop was organised with the aim of understanding and discussing the technological performance parameters with the entire group. In that workshop some common problems were identified, common for the entire group and for some enterprises that were grouped in sub-groups. By the end of this activity an action plan was established to increase lower performance parameters of the group. The action plan was extended to each enterprise identifying its own weaknesses.

The above-mentioned planned actions are being currently implemented. To improve the efficiency of the milling and $\mathrm{CNC}$ programming technology, specific work is being implemented, directly on the shop floor. Routines for tool life monitoring procedures to calculate the best cost / benefit relation of different tools were developed. Milling strategies for different surface features (pockets, ramps, cavities, etc.) were also created, and a study of suitable machining parameters, considering three different work-piece materials is being carried out.

\subsection{Contribution for the VO context}

One important contribution for the VO context is related to the entrepreneurs' behavioural change. Since the application of the questionnaire, analysis and activities after the initial benchmarking results, the entrepreneurs and employees change their behaviour from an initial posture of hiding information, to a frank exposure of confidential technological issues.

Some common technological problems that could be solved sharing experiences and best practices of the benchmarks were identified. The benchmarks accept to receive the visit of the other employees in order to show their best practices. With this experience they have the intention to share their knowledge using ICT through the VO participants. Additionally, were identified other kind of problems that could be solved by joining competencies and efforts in a co-operative way.

With this benchmarking experience the entrepreneurs are now convinced that working as a VO, not only aiming at reaching business opportunities, but also increasing their performance sharing their best practices, mainly in technological aspects, is a good alternative to become more competitive in the global market.

\section{CONCLUSIONS}

With the benchmarking project more than 100 benchmarking analyses were obtained, describing technological performances that could influence the competitiveness of the mould and die enterprises composing Virfebras.

The authors of this work believe that one result of this benchmarking project reflects in terms of o rganisational and technological s trategies. Some of them a re already being adopted by the enterprises within Virfebras.

Another important result of this work is the behavioural change that entrepreneurs went thorough. In the beginning of the project it was common to observe that entrepreneurs and employees used to hide information from the 
competitors, as time passed, they realised that this behaviour should be replaced by a new one, more suitable for a co-operative environment. They started sharing information and learned that they u sually have, if not the s ame problems, at least similar ones. If they started sharing solutions, every company could benefit from this exchange process. Nowadays entrepreneurs usually share information, once in a while one of them invites the other partners to visit its industry to show its resources and internal processes. The intention is to use the ICT in order to speed up the knowledge sharing. Actually, with this initiative Virfebras VO is studying the possibility to implement a Knowledge Management program.

Finally, it has been possible to observe a significant behavioural change in all Virfebras participants; one of the major changes is related to trust. The evolution of the entrepreneurs' behaviour when dealing with internal or particular issues is remarkable. That's why, the a uthors of the present work, state that benchmarking should be consider as a strategic activity to increase the integration and performance of enterprises that are involved in a VO.

\section{Acknowledgements}

The authors would like to thank SEBRAE-RS for its support to the benchmarking project. Also, we are very grateful to the Virfebras enterprises whose participation has been fundamental for the success of this project.

\section{REFERENCES}

1. Boxwell, R. Jr., Vantagem competitiva através do benchmarking. São Paulo: Makron Books, 1996.

2. Camarinha-Matos L. M., Afsarmanesh H. The virtual enterprise concept. In L. M. Camarinha-Matos, H. Afsarmanesh (Eds.), Infrastructures for Virtual Enterprises - Networking Industrial Enterprises, Kluwer Academic Publishers, 1999, p. 3-14.

3. Eversheim, W., Geschke, H.-J., Bilsing, A., Deckert, C., Westekemper, M. Vom Komponentenfertiger zum Systemlieferanten - Strategische Austichtung des Werkzeugbaus der Hettich Umformtechnik. In: Form + Werkzeug, 2001.

4. Eversheim, W., Klocke, F. Werkzeugbau mit Zukunft - Strategie und Technologie, Springer Verlag, Berlin, 1998.

5. Eversheim, W., Weber, P. The right strategy to success - Strategic orientation in die and mould manufacturing, presentation of the colloquium "Werkzeugbau mit Zukunft", Aachen, 22.-28. September 2000

6. Galelli, A., Costa, C. A., Vallejos, R. V., Graciolli, O. D., Luciano, M. A. "A Virtual Organisation for the Mold and Die Industry in Brazil". In: $5^{\mathrm{TH}}$ World Multiconference on Systemics, Cybemetics and Informatics/ISAS - SCI 2001. Orlando, FL: International Institute of Informatics and Systemics, 2001 v. III, p. 303-308.

7. Kiesel, $\mathrm{H}$. The Development Tendencies at the Tooling Shop of Daimler-Crysler do Brasil Ltda. Presentation at the $6^{\text {th }}$ International Seminar "High Technology", Piracicaba, Brazil, 2001.

8. Klocke, F.; Bilsing, A. Technologisches Benchmarking im Werkzeug- und Formenbau, WT. Werkstattstechnik 92, Nr.11/12, p.595-599.

9. Spendolini, Michael Jr. Benchmarking. Tradução de Kátia Aparecida Roque. São Paulo: Makron Books, 1993.

10. Zairi, M ., Leonard, P. Practical Benchmarking: The Complete Guide. London: Chapman \& Hall, 1996. 